SUBJECT AREAS:

ELECTRICAL AND

ELECTRONIC

ENGINEERING

ELECTRONIC DEVICES

Received

28 October 2013

Accepted

4 March 2014

Published

1 April 2014

Correspondence and requests for materials should be addressed to H.J.K. (hjk3@yonsei. ac.kr)

\section{Transparent Amorphous Oxide Thin-Film Transistors Obtained by Sol-Gel Process}

\author{
Hyun Soo Lim, You Seung Rim \& Hyun Jae Kim
}

School of Electrical and Electronic Engineering, Yonsei University, 50 Yonsei-ro, Seodaemun-gu, Seoul 120-749, Korea.

We demonstrated self-patterned solution-processed amorphous oxide semiconductor thin-film transistors (TFTs) using photosensitive sol-gels. The photosensitive sol-gels were synthesized by adding $\boldsymbol{\beta}$-diketone compounds, i.e., benzoylacetone and acetylacetone, to sol-gels. The chemically modified photosensitive sol-gels showed a high optical absorption at specific wavelengths due to the formation of metal chelate bonds. Photoreactions of the modified solutions enabled a photoresist-free process. Moreover, $\mathrm{Zn}-\mathrm{Sn}-\mathrm{O}$ with a high Sn ratio, which is hard to wet-etch using conventional photolithography due to its chemical durability, was easily patterned via the self-patterning process. Finally, we fabricated a solution-processed oxide TFT that included fully self-patterned electrodes and an active layer.

- he increasing demand for advanced displays, such as active matrix organic light-emitting diode (AMOLED) displays, drives the development of high-performance thin-film transistors (TFTs), which are required for their operation ${ }^{1,2}$. Amorphous oxide semiconductor (AOS)-based TFTs are considered to be the most likely devices for next-generation displays due to their high mobility and transparency. Therefore, since the report of an In-Ga-Zn-O (IGZO) TFT in 2004, AOS TFTs have been widely investigated, culminating in the recent mass production of displays using vacuum-processed AOS TFTs ${ }^{3-5}$. However, solution-processed AOS (SAOS) TFTs have not been adopted industrially due to their poor film quality, uniformity, reliability, and performance despite their definite advantages of low cost and simple processing. Consequently, many approaches for improving the performance of SAOS TFTs have been reported ${ }^{6-12}$; however, the manufacturing process has not been thoroughly investigated even though the cost and process efficiency are significant factors. Thus, in this study, we focused on maximizing the processing advantages of SAOS TFTs.

The primary advantage of solution processing is that a photoresist (PR)-free self-patterning process can be applied by using a photosensitive sol-gel ${ }^{13-15,32}$ : The photosensitive sol-gel acts as a PR, which negates the need for a PR to obtain micro-patterns. Thus, by using this method, cost-effective process simplification could be realized by eliminating the PR required for conventional photolithography. Among the many approaches to synthesize photosensitive sol-gel, we used the one that involves the addition of $\beta$-diketone compounds such as benzoylacetone (1-phenyl-1,3-butanedione, BzAc) ${ }^{13-19}$ and acetylacetone (pentane-2,4-dione, AcAc) ${ }^{20-22}$. By using $\beta$ diketone compounds in metal precursor solutions, photosensitive sol-gels were easily produced via the formation of metal chelate bonds. Previously, this method was studied for transparent conducting oxide (TCO) and ferromagnetic or insulator applications; however, it has not been applied to TFT device fabrication ${ }^{13-22}$.

In this study, we introduce the characteristics and fabrication of self-patternable SAOS TFTs using $\beta$-diketone compounds. In order to fabricate the self-patternable SAOS TFTs, BzAc and AcAc were used as photo-activators for the synthesis of photosensitive sol-gels. We prepared a Zn-Sn-O (ZTO) material because Sn-based AOSs are more cost-efficient than In-based AOSs, which suffer from the limited natural abundance of In. Generally, Snbased AOSs are hard to wet-etch to obtain fine patterns due to the high chemical durability of Sn-O ${ }^{19,21}$. However, this problem was easily overcome by using the self-patterning method. Finally, we demonstrated both a fully selfpatternable ZTO active layer and ITO source/drain (S/D) electrodes for TFTs.

\section{Results and discussion}

Figure 1 shows a schematic diagram of the formation of each metal chelate and the degradation mechanism of the metal salt precursors $\left(\mathrm{MX}_{\mathrm{n}} ; \mathrm{n}=4\right)$ with $\beta$-diketone compounds. The combination of $\mathrm{MXn}$ with $\beta$-diketone compounds, such as BzAc and AcAc, to synthesize a photosensitive metal precursor solution results in the 
(a)

(b)<smiles></smiles>

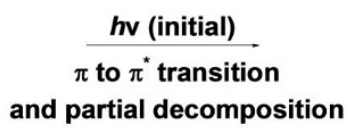<smiles></smiles>

$\pi$ to $\pi^{*}$ transition and partial decomposition
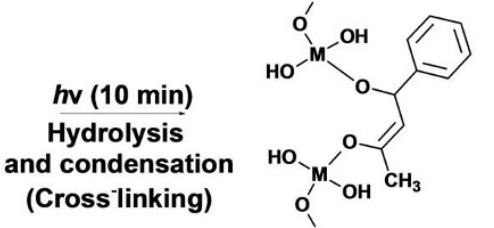

$+\mathrm{H}_{2} \mathrm{O}$ (Cross linking)

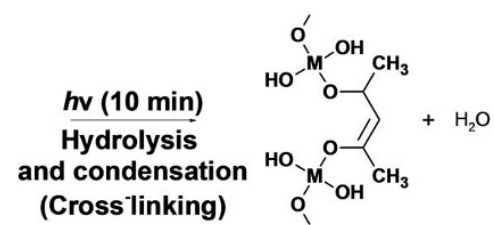

Figure 1 Schematic diagram of the cross-linking mechanisms of (a) BzAc and (b) AcAc in a metal precursor $\left(\mathrm{MX}_{\mathrm{n}}\right)$ solutions.

exchange of the $\mathrm{X}$ ligands, such as acetate $\left(\mathrm{CH}_{3} \mathrm{COO}^{-}\right)$, nitrate $\left(\mathrm{NO}_{3}{ }^{-}\right)$, and chloride $\left(\mathrm{Cl}^{-}\right)$, with $\beta$-diketonato ligands along with the formation of acid byproducts to form polymerized metal chelate bonds ${ }^{23}$. After chelate formation, the metal chelates have ring structures with each metal ion surrounded with $\beta$-diketonato ligands, i.e., $\mathrm{BzAc}^{-}$or $\mathrm{AcAc}^{-}$, as depicted in Figure 1. The metal chelate bonds with the $\beta$-diketonato ligands result in the unique photosensitivity of each sol-gel at a specific wavelength due to the $\pi \rightarrow \pi^{*}$ electronic transition: Exposure of the chemically modified gel films containing $\beta$-diketone compounds to ultraviolet (UV) light of the proper wavelength causes the $\pi \rightarrow \pi^{*}$ electronic transition to occur in each metal chelate bond. It has been reported that the excited electrons are partially redistributed to the oxygen side during the $\pi \rightarrow \pi^{*}$ electronic transition, which reduces the coordination strength of between the metal cation and $\beta$-diketonato ligand bond. Consequently, the $\beta$-diketonato ligands dissociate from the metal cation and the metal chelate bonds gradually decompose due to UV irradiation ${ }^{17,18}$

To observe these phenomena, we analyzed the optical absorption spectra using UV-Vis spectroscopy. As shown in Figure 2, the optical absorption changes of the ITO and ZTO gel films with BzAc and AcAc, which originate from metal chelation and cross-linking, are clearly evident. As the mole ratios of BzAc and AcAc in ITO and ZTO solutions, i.e., [BzAc] $/[\mathrm{In}+\mathrm{Sn}]$ and $[\mathrm{AcAc}] /[\mathrm{Zn}+\mathrm{Sn}]$, respectively, increased, the absorbance of the ITO and ZTO gel films at 328 and $308 \mathrm{~nm}$, respectively, drastically increased; this increase is attributed to the formation of metal chelate rings composed of metal cations (i.e., $\left.\mathrm{In}^{3+}, \mathrm{Sn}^{2+}, \mathrm{Zn}^{2+}\right), \mathrm{BzAc}-$, and $\mathrm{AcAc}-$ : $\operatorname{In}(\mathrm{BzAc})\left(\mathrm{NO}_{3}\right)_{2}$, $\mathrm{Sn}(\mathrm{BzAc}) \mathrm{Cl}, \mathrm{Zn}(\mathrm{AcAc}) \mathrm{CH}_{3} \mathrm{COO}$, and $\mathrm{Sn}(\mathrm{AcAc}) \mathrm{Cl}^{16,18,21}$. It has been previously reported that metal chelate bonds involving BzAc and AcAc were resistant to hydrolysis ${ }^{27}$; however, in both cases in this study, the increased absorption with the addition of BzAc and AcAc drastically decreased after UV irradiation for $10 \mathrm{~min}$, indicating the decomposition of the metal chelate ring, as mentioned above. Thus, cleavage of the metal chelate bonds in complexes such as $\mathrm{In}(\mathrm{BzAc})\left(\mathrm{NO}_{3}\right)_{2}, \mathrm{Sn}(\mathrm{BzAc}) \mathrm{Cl}, \mathrm{Zn}(\mathrm{AcAc}) \mathrm{CH}_{3} \mathrm{COO}$, and $\mathrm{Sn}(\mathrm{AcAc}) \mathrm{Cl}$ occurred due to the attenuation of the coordination strength during cross-linking. It should be noted that the dissociation of metal chelate bonds leads to the hydrolysis of ITO and ZTO films and thus contributes to the generation of fine patterns ${ }^{16-22}$.

To clarify the photo-reactive behavior of the metal chelate bonds, Fourier transform infrared (FT-IR) spectra were measured for the ZTO gel films with AcAc. Since the metal chelate bonds comprise a coordination bond between the metal cation and the oxygen atoms in the $\beta$-diketonato ligands, the formation and dissociation of metal chelate bonds could be confirmed by observing changes in the absorption peaks derived from the metal oxygen vibrations in the FT-IR spectrum. It has been reported that the absorption band related to the metal-oxygen stretching vibration in metal chelate bonds is observed in the region below $700 \mathrm{~cm}^{-124-26}$. As shown in Figure 3, the absorption peaks that are newly generated after the addition of AcAc to ZTO sol-gel were observed at 567, 572, 590, and $605 \mathrm{~cm}^{-1}$ (numbers were bolded) comparing pristine ZTO gel film without AcAc. However, these peaks nearly disappeared after 10 min of UV irradiation. And then, the peak spectra of the ZTO gel film with AcAc showed similar with pristine ZTO gel film, i.e., 553,

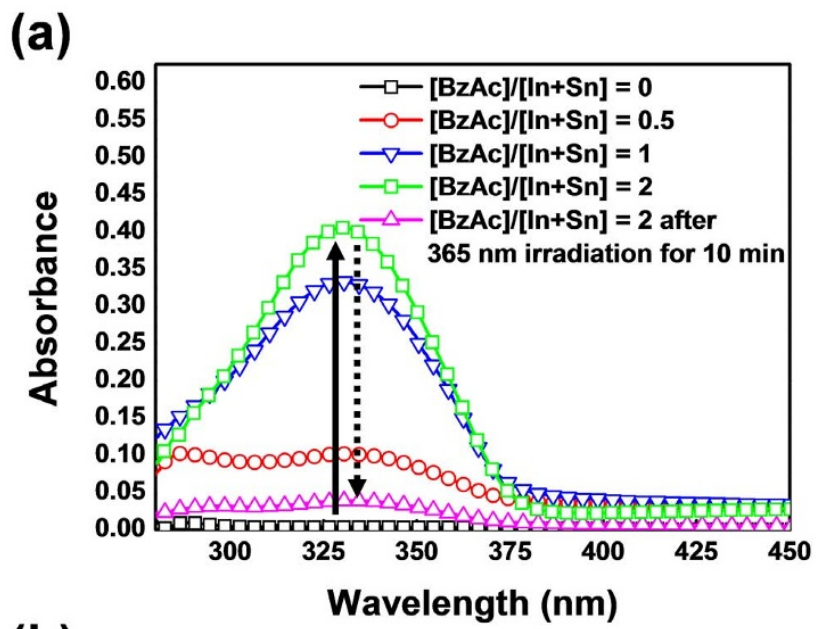

(b)

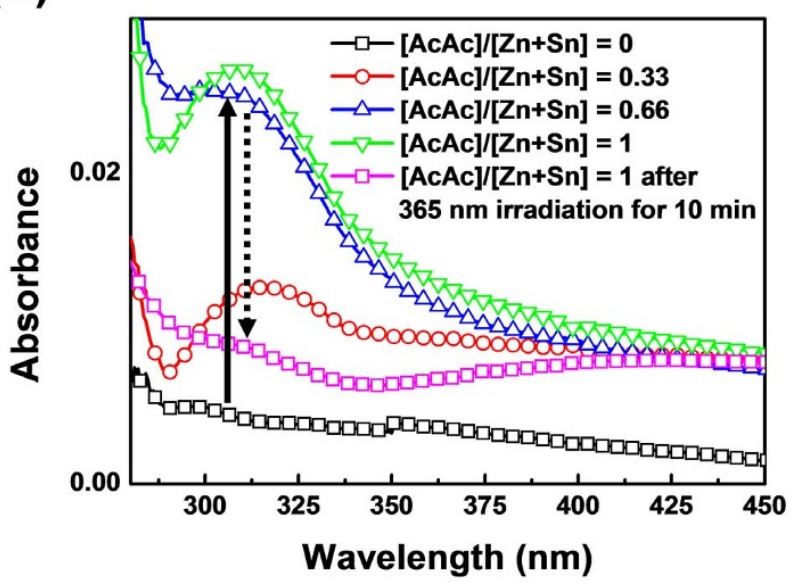

Figure $2 \mid$ Optical absorption spectra of the (a) ITO gel films as a function of $[\mathrm{BzAc}] /[\mathrm{In}+\mathrm{Sn}]$ and ITO gel films with $[\mathrm{BzAc}] /[\mathrm{In}+\mathrm{Sn}]$ of $2 \mathrm{after}$ UV irradiation for $10 \mathrm{~min}$, and (b) ZTO gel films as a function of [AcAc]/ $[\mathrm{Zn}+\mathrm{Sn}]$ and ZTO gel films with [AcAc]/[In $+\mathrm{Sn}]$ of 1 after UV irradiation for $10 \mathrm{~min}$. The optical absorption spectra were obtained via UV-Vis spectroscopy. 


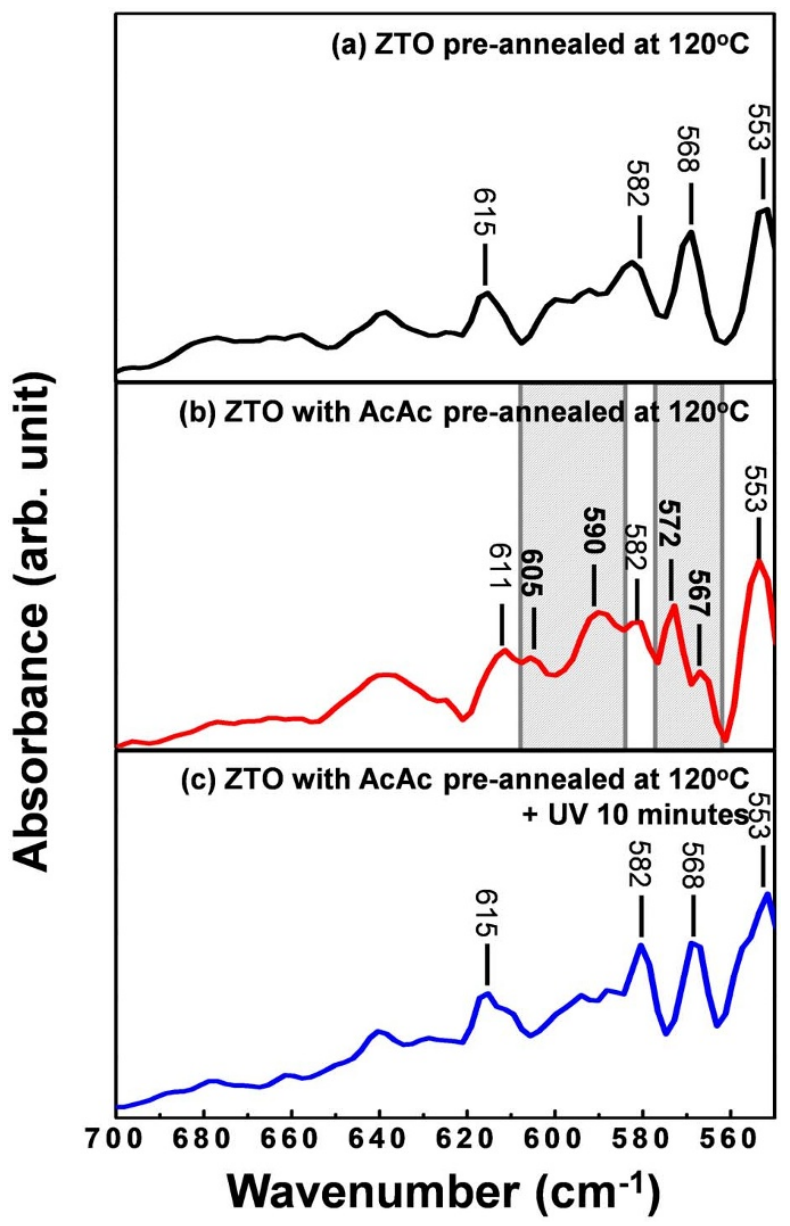

Figure 3 FT-IR absorption spectra of the (a) pristine ZTO gel film, (b) ZTO gel film with [AcAc]/[In + Sn] of 0.33 , and (c) ZTO gel film with $[$ AcAc] $] /[\mathrm{In}+\mathrm{Sn}]$ of 0.33 after UV irradiation for $10 \mathrm{~min}$. All samples were pre-annealed at $120^{\circ} \mathrm{C}$ to exclude solvent-related peaks.

568,582 , and $615 \mathrm{~cm}^{-1}$. This indicates that decomposition of the $\beta$ diketone occurred under UV, which correlates with the UV-Vis spectroscopic results.

Figure 4 shows scanning electron microscopy (SEM) images of the ITO and ZTO thin film patterns on Si substrate using the photosensitive ITO and ZTO sol-gels. During UV irradiation, the dissociation of the chelate rings easily occurred in the ITO and ZTO gel films ${ }^{17}$. Thus, the UV-irradiated regions of the ITO and ZTO gel films become cross-linked, as shown in Figure 1, and become barely soluble in their own solvent. Due to the solubility differences between the irradiated and non-irradiated parts, negative-type patterns of ITO and ZTO thin films could be obtained. The minimum feature size of the ITO and ZTO thin films was $\sim 5 \mu \mathrm{m}$.

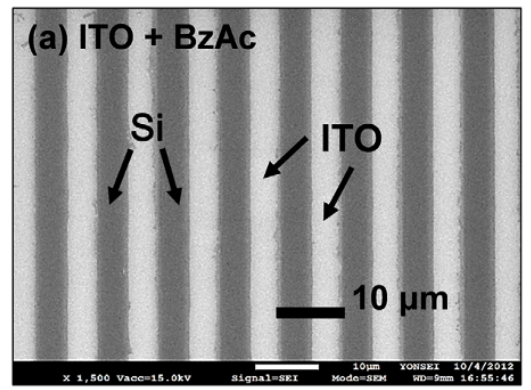

(a)

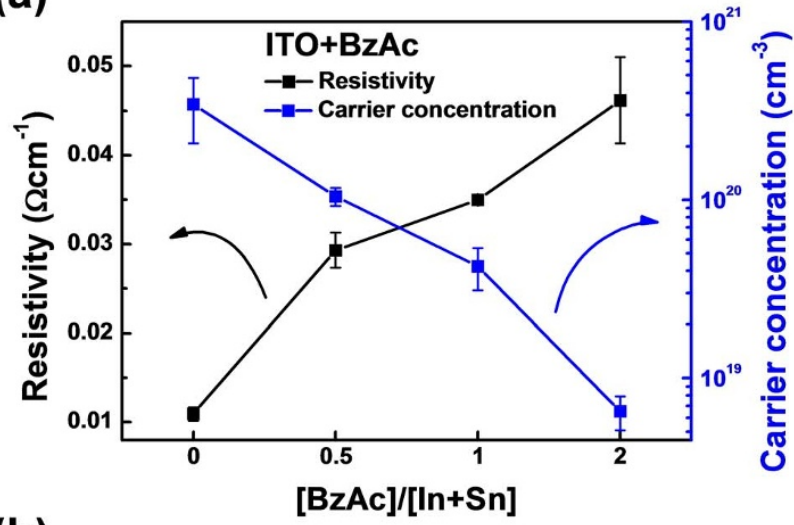

(b)

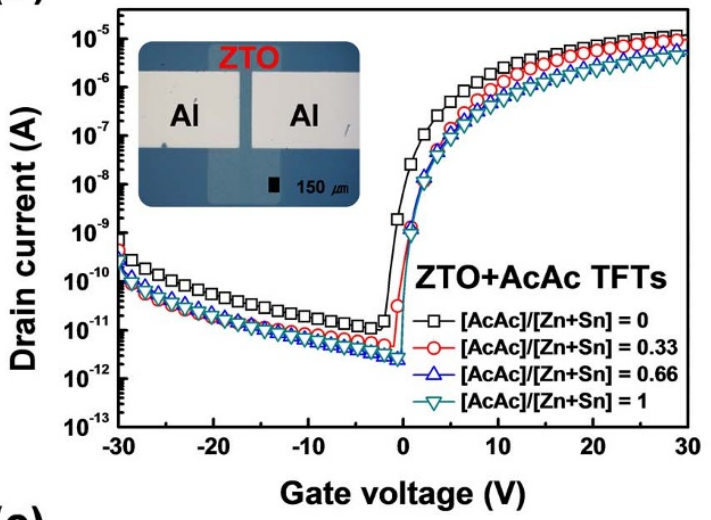

(c)

Gate voltage (V)

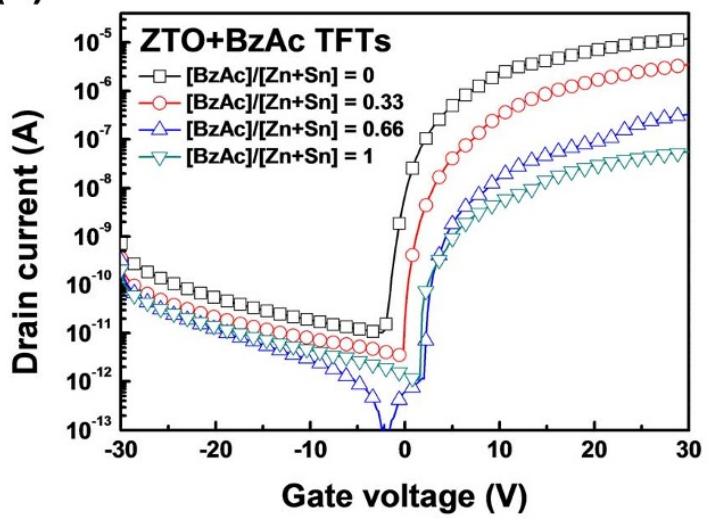

Figure $5 \mid$ (a) The variation of resistivity and carrier concentration of the ITO thin films as a function of $[\mathrm{BzAc}] /[\mathrm{In}+\mathrm{Sn}]$. The transfer curves of the self-patterned ZTO TFTs as a function of (b) $[\mathrm{AcAc}] /[\mathrm{Zn}+\mathrm{Sn}]$ and (c) $[\mathrm{BzAc}] /[\mathrm{Zn}+\mathrm{Sn}]$. The inset of $(\mathrm{b})$ is the optical microscopy image of the self-patterned ZTO TFT.

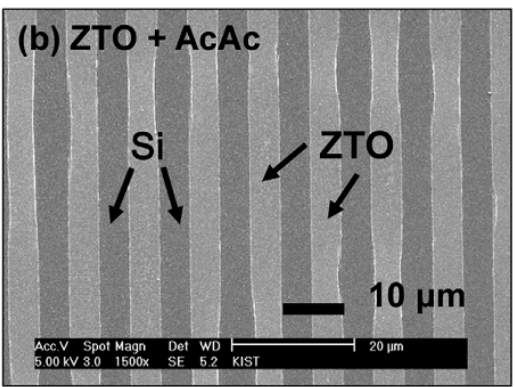

Figure $4 \mid$ SEM images of the (a) ITO and (b) ZTO patterns obtained via the self-patterning process. 
(a)

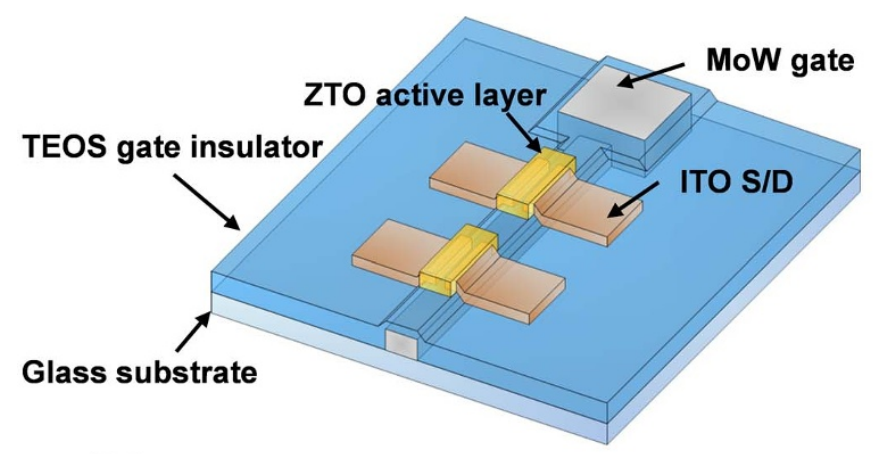

(b)

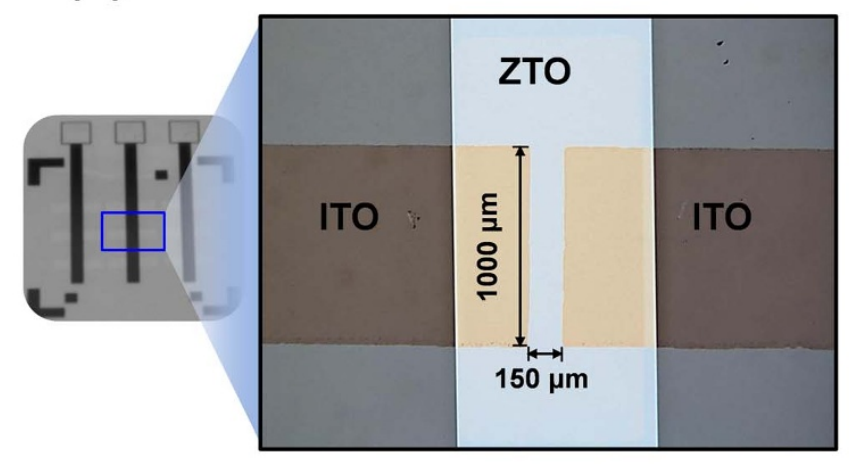

(c)

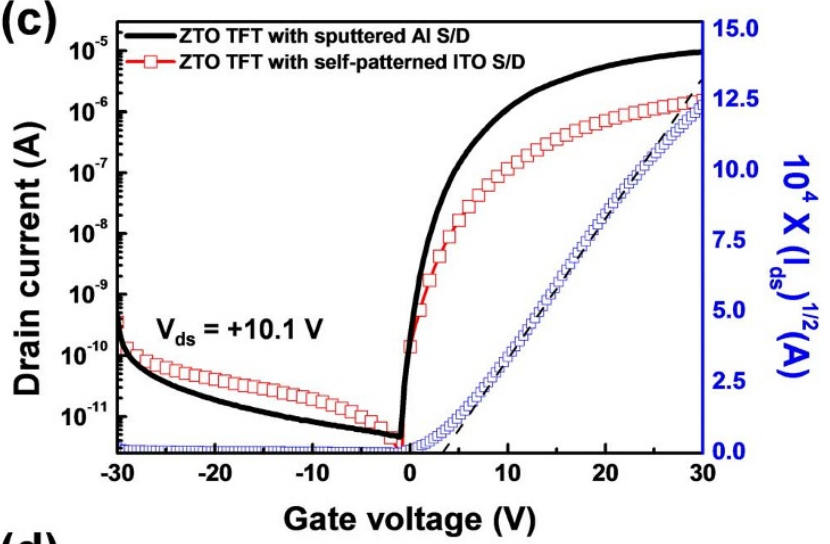

(d)

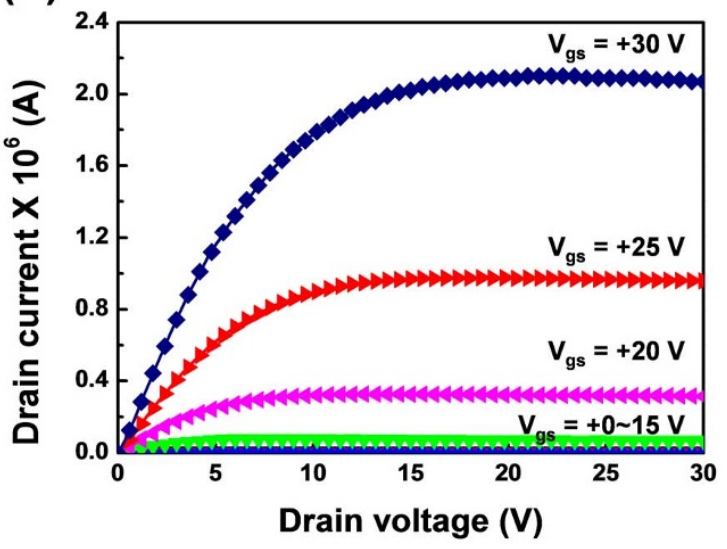

Figure 6 | Fully self-patterned SAOS TFTs with a self-patterned ZTO active layer and ITO S/D electrodes. (a) Schematic of the device structure and (b) optical microscopy images of the fabricated device. (c) Comparison of the transfer characteristics of the self-patterned ZTO TFTs with ITO and Al S/D electrodes. (d) Output characteristics of the self-patterned ZTO TFTs with ITO S/D electrodes.

To verify the applicability of UV-patterned ITO and ZTO thin films for TFTs, the electrical characteristics of the films were evaluated as S/D electrodes and active layers, respectively. If the BzAc and AcAc moieties in the ITO and ZTO sol-gels are not completely decomposed and evaporated during annealing, they could leave organic residues that would degrade the electrical characteristics of the films ${ }^{30}$. For the ITO thin films modified with BzAc, the bulk carrier concentration and resistivity were measured as a function of $[\mathrm{BzAc}] /[\mathrm{In}+\mathrm{Sn}]$ using the Hall effect measurement. As shown in Figure 5(a), the electrical degradation of ITO thin film is evident as the increase of $[\mathrm{BzAc}] /[\mathrm{In}+\mathrm{Sn}]$. As $[\mathrm{BzAc}] /[\mathrm{In}+\mathrm{Sn}]$ increases from 0 to 2 , the bulk carrier concentration of the ITO thin film gradually decreases from $3.45 \times 10^{20}$ to $6.52 \times 10^{18}$. Also, due to the decreased bulk carrier concentration, the resistivity of the ITO thin film increased from $1.1 \times 10^{-2}$ to $4.6 \times 10^{-2} \Omega \cdot \mathrm{cm}^{-1}$. The degradation of the electrical conductivity of the ITO thin films is attributed to the incomplete decomposition of the $\mathrm{BzAc}^{-}$ligands and insufficient volatilization of BzAc from the ITO thin films. If the metal chelate bonds are formed with $\beta$-diketone compounds, hydrolysis of the solution can be suppressed, because the particle growth from the monomers to oligomers that contain metal-oxygen-metal bridges hindered by the chelate bonds ${ }^{27-29}$. As shown in Figure 2, absorption due to metal chelate bonds remained after UV irradiation. Thus, the coordinated $\mathrm{BzAc}^{-}$ligands suppressed the hydrolysis and gelation of the ITO solutions resulting in insufficient ITO formation, which lowers the electrical conductivity. In the case of ZTO thin films modified with AcAc, ZTO TFTs were fabricated at $350^{\circ} \mathrm{C}$ with varying $[\mathrm{AcAc}] /[\mathrm{Zn}+\mathrm{Sn}]$ to observe the effect on the ZTO TFTs. All the ZTO thin films with AcAc were patterned using the self-patterning process, except the pristine ZTO thin film, because ZTO thin films with a high Sn ratio $(\sim 33 \%)$ were difficult to pattern using the conventional wet-etching process. As shown in Figure $5(\mathrm{~b})$, a slight degradation in the saturation mobility $\left(\mu_{\mathrm{sat}}\right)$ of the ZTO TFTs was observed; This is not significant considering the overestimation of $\mu_{\text {sat }}$ by fringing current in non-patterned pristine ZTO TFT. However, the electrical performance of the ZTO TFTs with BzAc was significantly lower than that of ZTO TFTs with AcAc, as shown in Figure 5(c). Detailed parameters of ZTO TFTs with BzAc and AcAc are shown in supplementary section (Table S1 and S2). Since AcAc has lower boiling point $\left(\mathrm{T}_{\mathrm{bp}}=140^{\circ} \mathrm{C}\right)$ than BzAc $\left(\mathrm{T}_{\mathrm{bp}}=\right.$ $263^{\circ} \mathrm{C}$ ), AcAc could be decomposed and evaporated easier than BzAc during the annealing process ${ }^{15}$. Thus, the organic residues that originate from AcAc were relatively insignificant compared to those of BzAc, and thus did not have as significant an effect on the electrical performance of the ZTO TFTs regardless of the amount of AcAc. These results are consistent with C1s XPS peaks of films with different additives (supplementary Figure S3) ${ }^{30}$. Also, it has been reported that the increase in the hydrolysis induction time after the addition of AcAc addition is ten times less than with $\mathrm{BzAc}^{28}$; this implies that the hydrolysis of solutions containing AcAc is easier than those with BzAc and the suppression of hydrolysis during the sol-gel process would be diminished. Thus, AcAc is more suitable than BzAc as a photosensitizer in the ZTO active layer.

Finally, a fully self-patterned SAOS TFT, i.e., both the S/D electrodes and active layer were fully self-patterned, was fabricated, as shown in Figure 6(a). The synthesized ITO and ZTO sol-gels were used as the S/D electrodes and active layer, respectively. The ITO solution with [BzAc] $/[\mathrm{In}+\mathrm{Sn}]$ of 0.5 and the ZTO solution with $[\mathrm{AcAc}] /[\mathrm{Zn}+\mathrm{Sn}]$ of 0.33 were used to minimize the degradation of the electrical characteristics while guaranteeing the patternability of 
the ITO and ZTO films. To prevent damaging the ZTO active layer during the subsequent ITO self-patterning process, the ITO S/D electrodes were deposited before the ZTO active layer was formed. Thus, the fully self-patterned SAOS TFT had a bottom-gate/coplanar structure and was highly transparent in all parts of the device except for the MoW gate electrodes, as shown in Figure 6(b). Figures 6(c) and (d) show the transfer characteristics and output characteristics of the fully self-patterned SAOS TFT, respectively. In comparison with the self-patterned ZTO TFT with sputtered Al S/D electrodes, degradation was observed in the fully self-patterned SAOS TFT and is attributed to increased contact resistance between the ZTO active layer and ITO S/D electrodes due to the inter-diffusion phenomenon and the Fermi level shift ${ }^{31}$. However, the fully self-patterned SAOS TFT showed clear switching characteristics. The fully self-patterned SAOS TFT had a saturation mobility of $0.03 \mathrm{~cm}^{2} / \mathrm{V} \cdot \mathrm{s}$, an on/off ratio of $6.85 \times 10^{5}$, a subthreshold swing (S.S) of $0.84 \mathrm{~V} /$ decade, and a threshold voltage $\left(\mathrm{V}_{\mathrm{th}}\right)$ of $3.94 \mathrm{~V}$. Also, the pinch-off and drain current $\left(\mathrm{I}_{\mathrm{ds}}\right)$ saturation were clearly evident in the output characteristics of the device. We demonstrated self-patterned SAOS TFTs using photosensitive ITO and ZTO sol-gels modified with $\beta$-diketone compounds such as BzAc and AcAc. The chemically modified ITO and ZTO solutions showed increased optical absorbance at specific wavelengths due to the formation of metal chelate bonds to form $\mathrm{In}(\mathrm{BzAc})\left(\mathrm{NO}_{3}\right)_{2}, \mathrm{Sn}(\mathrm{BzAc}) \mathrm{Cl}, \mathrm{Zn}(\mathrm{AcAc}) \mathrm{CH}_{3} \mathrm{COO}$, and $\mathrm{Sn}(\mathrm{AcAc}) \mathrm{Cl}$ complexes. Since the photosensitive ITO and ZTO solutions can act as PRs, an additional PR was not required to obtain micro-patterns of the ITO and ZTO thin films. Using the self-patterning method, ITO and ZTO patterns with $5 \mu \mathrm{m}$ resolution were obtained. Finally, we demonstrated a fully self-patterned ZTO TFT with ITO S/D electrodes; in this device, both S/D electrodes and the active layer were selfpatterned, and the device showed clear switching characteristics with a $\mu_{\text {sat }}$ of $0.03 \mathrm{~cm}^{2} / \mathrm{V} \cdot \mathrm{s}$ and an on/off ratio of $6.85 \times 10^{5}$. This work suggests the potential of self-patterned SAOS TFTs, which would maximize the compatibility of solution processing with industry.

\section{Methods}

Synthesis of solutions. ITO solutions $(0.3 \mathrm{M})$ were prepared by dissolving indium nitrate hydrate [ $\mathrm{In}\left(\mathrm{NO}_{3}\right)_{2} \cdot \mathrm{xH}_{2} \mathrm{O}$, Kojundo Chemical Laboratory Co.,Ltd., 99.95\%] and tin(II) chloride [ $\mathrm{SnCl}_{2}$, Aldrich, 99.99\%] in 2-methoxyethanol (2-ME, Aldrich, $99 \%)$, and ZTO solutions $(0.3 \mathrm{M})$ were prepared by dissolving zinc acetate dihydrate $\left[\mathrm{Zn}\left(\mathrm{CH}_{3} \mathrm{COO}\right)_{2} \cdot 2 \mathrm{H}_{2} \mathrm{O}\right.$, Aldrich, $98 \%$ ] and tin(II) chloride in 2-ME. The mole ratio between the two metal precursors of the ITO and ZTO solutions were fixed at $9: 1$ and $2: 1$, respectively. After mixing, the ITO and ZTO solutions were stirred for $1 \mathrm{~h}$ at $70^{\circ} \mathrm{C}$, after benzoylacetone (1-phenyl-1,3-butanedione, BzAc, Alfa Aesar, 98\%) and acetylacetone (pentane-2,4-dione, AcAc, Aldrich, 99\%) were added to the ITO and ZTO solutions, respectively, to obtain the desired photo-reactive characteristics. To verify the effect of BzAc and AcAc on the ITO and ZTO thin films, the mole ratio of BzAc in the ITO solution (i.e., [BzAc] $] /[\mathrm{In}+\mathrm{Sn}]$ ) was varied between 0 and 2 , and the mole ratio of AcAc in the ZTO solution (i.e., $[\mathrm{AcAc}] /[\mathrm{Zn}+\mathrm{Sn}]$ ) was varied between 0 and 1 . The chemically modified ITO and ZTO solutions were then stirred for $1 \mathrm{~h}$ at room temperature. Finally, the ITO and ZTO solutions were filtered through a $0.2 \mu \mathrm{m}$ syringe filter and aged for $24 \mathrm{~h}$ to form the chelating agents in the solutions.

Self-patterning process. For the ITO films, the ITO solutions were spin-coated onto the prepared silicon substrate at $1500 \mathrm{rpm}$ for $30 \mathrm{~s}$. The ITO-coated samples were then pre-baked at $120^{\circ} \mathrm{C}$ for $5 \mathrm{~min}$ to evaporate the solvent. After pre-baking, the ITO gel films were hard-contacted to a photomask to obtain high-resolution patterns and then irradiated using a UV lamp $\left(365 \mathrm{~nm}, 48 \mathrm{~mW} / \mathrm{cm}^{2}\right)$ for $10 \mathrm{~min}$. The UVirradiated samples were then immediately leached in 2-ME for 2-5 min and rinsed with deionized (DI) water. During the leaching process, the UV-irradiated parts of the ITO gel films remained while the un-irradiated part dissolved into 2-ME, as mentioned above. Finally, the patterned ITO gel films were annealed at $500^{\circ} \mathrm{C}$ for $2 \mathrm{~h}$ in air. The process for the self-patterning of the ZTO and ITO films was the same except for the spin-coating conditions and annealing temperatures: The prepared ZTO solutions were spin-coated at $3000 \mathrm{rpm}$ for $30 \mathrm{~s}$, and the ZTO thin films were annealed at $350^{\circ} \mathrm{C}$ for $2 \mathrm{~h}$ in air.

TFT fabrication. To identify the effects of the addition of AcAc to ZTO TFTs, ZTO TFTs with various $[\mathrm{AcAc}] /[\mathrm{Zn}+\mathrm{Sn}]$ were fabricated. The prepared ZTO solutions with AcAc were spin-coated at $1500 \mathrm{rpm}$ for $30 \mathrm{~s}$ onto a silicon dioxide $\left(\mathrm{SiO}_{2}\right)$ layer (gate dielectric, 120-nm-thick) that was thermally grown onto a heavily boron (B) doped $p$-type silicon wafer $(p+S i)$. The $p+S i$ substrate was used as the gate electrode for the ZTO TFTs. To fabricate the active layer, the ZTO thin films (25-nm- thick) were formed using the patterning processes described above. After the formation of the ZTO active layer, aluminum (Al) S/D electrodes with a thickness of $200 \mathrm{~nm}$ and a channel width/length (W/L) of 1000/150 $\mu \mathrm{m}$ were deposited using the RF-magnetron sputtering method. The ZTO TFTs had conventional bottom-gate and top-contact structures. To fabricate the ZTO TFT with ITO S/D electrodes, a 200nm-thick patterned MoW gate electrode was formed on a glass substrate that had a $\mathrm{SiO}_{2}$ buffer layer. As the gate dielectric, a 120-nm-thick tetraethyl orthosilicate (TEOS) layer was deposited via plasma-enhanced chemical vapor deposition on the MoW patterns. A 25-nm-thick ZTO active layer was then formed on top of the TEOS layer using the self-patterning process mentioned above with an annealing temperature of $500^{\circ} \mathrm{C}$ for $2 \mathrm{~h}$ in air. After the formation of the ZTO active layer, 40 $\mathrm{nm}$-thick ITO S/D electrodes were also formed using the patterning processes described above.

Measurements and characterization. The characteristics of the fabricated ZTO TFTs were measured using a semiconductor parameter analyzer (Agilent, HP 4156C) in a dark room under ambient conditions. The transfer characteristics of the TFT devices were measured under a drain voltage $\left(\mathrm{V}_{\mathrm{ds}}\right)$ of $10.1 \mathrm{~V}$ and the gate voltage $\left(\mathrm{V}_{\mathrm{gs}}\right)$ was swept from -30 to $+30 \mathrm{~V}$. The $\mu_{\text {sat }}$ was calculated using the following equation:

$$
\mathrm{I}_{\mathrm{ds}}=\frac{\mathrm{W}}{2 \mathrm{~L}} \mathrm{C}_{\mathrm{i}}^{\prime} \mu_{\mathrm{sat}}\left(\mathrm{V}_{\mathrm{gs}}-\mathrm{V}_{\mathrm{th}}\right)^{2},
$$

where $\mathrm{C}_{\mathrm{i}}$ is the capacitance of the gate dielectric per unit area, $\mathrm{W}$ is the channel width, and $\mathrm{L}$ is the channel length. The threshold voltage $\left(\mathrm{V}_{\mathrm{th}}\right)$ of the TFT devices was determined by extrapolating the linear line with the maximum slope in the $V_{g s}$ versus $\left(\mathrm{I}_{\mathrm{ds}}\right) 1 / 2$ plot. The $\mathrm{S} . \mathrm{S}$ value was calculated using the following equation: $\mathrm{S} . \mathrm{S}=$ $\log \left(\partial \mathrm{V}_{\mathrm{gs}} / \partial \mathrm{I}_{\mathrm{ds}}\right) 10$. Finally, the output characteristics were obtained by sweeping the $\mathrm{V}_{\mathrm{ds}}$ from 0 to $30 \mathrm{~V}$ under $\mathrm{a} \mathrm{V}_{\mathrm{gs}}$ of $\sim+0-30 \mathrm{~V}$. The optical absorbance of the ITO and ZTO thin films in the UV-Vis range were measured using a UV-Vis spectrophotometer (JASCO, V-650). The changes in the chemical bonding state were observed using an FT-IR spectrometer (Bruker, Vertex 70) with a ZnSe crystal attenuated total reflectance (ATR) unit. The pattern images of the ITO and ZTO thin films were obtained via SEM (FEI, XL-30 FEG). The electrical characteristics of the ITO thin films were estimated using the Hall-effect measurement system with the four-point probing method (Ecopia, HMS-3000). To obtain valid Hall-effect results, we used the mean value of resistivity and $\mathrm{N}_{\text {bulk }}$ of the ITO thin film obtained from 10 times repeats per sample. The chemical properties of films were determined using Xray photoelectron spectroscopy (XPS, ESCALAB 220I XL, VG Scientific) using monochromatic $\mathrm{Al} \mathrm{K} \alpha$ radiation $(1486.6 \mathrm{eV})$ under ultra-high vacuum $\left(2 \times 10^{-10}\right.$ Torr).

1. Fortunato, E., Barquinha, P. \& Martins, R. Oxide semiconductor thin-film transistors: A review of recent advances. Adv. Mater. 24, 2945 (2012).

2. Kamiya, T., Nomura, K. \& Hosono, H. Present status of amorphous In-Ga-Zn-O thin-film transistors. Sci. Technol. Adv. Mater. 11, 044305 (2010).

3. Nomura, K. et al. Room-temperature fabrication of transparent flexible thin-film transistors using amorphous oxide semiconductors. Nature 432, 488 (2004).

4. Park, J.-S. et al. Novel ZrInZnO Thin-film transistor with excellent stability. $A d v$. Mater. 21, 329 (2009).

5. Mativenga, M., Choi, J. W., Hur, J. H., Kim, H. J. \& Jang, J. Highly stable amorphous-indium-gallium-zinc-oxide thin-film transistor using an etch stopper and a via-hole structure. J. Inf. Display 12, 47 (2011).

6. Banger, K. K. et al. H. Low-temperature, high-performance solution-processed metal oxide thin-film transistors formed by a 'sol-gel on chip' process. Nature Mater. 10, 45 (2011).

7. Kim, M.-G. et al. Low-temperature fabrication of high-performance metal oxide thin-film electronics via combustion processing. Nature Mater. 10, 382 (2011).

8. Han, S.-Y., Herman, G. S. \& Chang, C.-H. Low-Temperature, High-performance, solution-processed indium oxide thin-film transistors. J. Am. Chem. Soc. 133, 5166 (2011).

9. Park, S. Y. et al. Low-Temperature, Solution-processed and alkali metal doped $\mathrm{ZnO}$ for high-performance thin-film transistors. Adv. Mater. 24, 834 (2012).

10. Jeong, W. H., Bae, J. H. \& Kim, H. J. High-performance oxide thin-film transistors using a volatile nitrate precursor for low-temperature solution process. IEEE Electron Device Lett. 33, 68 (2012).

11. Kim, G. H. et al. Inkjet-printed InGaZnO thin film transistor. Thin Solid Films 517, 4007 (2009).

12. Choi, Y. et al. Characteristics of gravure printed $\mathrm{InGaZnO}$ thin films as an active channel layer in thin film transistors. Thin Solid Films 518, 6249 (2010).

13. Jung, Y. et al. Direct photopatternable organic-inorganic hybrid gate dielectric for solution-processed flexible $\mathrm{ZnO}$ thin film transistors. J. Mater. Chem. 21, 11879 (2011).

14. Depre, L., Kappel, J. \& Popall, M. Inorganic-organic proton conductors based on alkylsulfone functionalities and their patterning by photoinduced methods. Electrochimica Acta 43, 1301 (1998).

15. Calzada, M. L., González, A., Poyato, R. \& Pardo, L. Photo-sensitive sol-gel solutions for the low-temperature UV-assisted processing of $\mathrm{PbTiO}_{3}$ based ferroelectric thin films. J. Mater. Chem. 13, 1451 (2003).

16. Li, Y., Zhao, G., Zhang, W. \& Chen, Y. Using the photolysis of chemically modified gel films preparing ITO fine patterned thin films. J. Disp. Technol. 2, 175 (2006). 
17. Chen, Y., Zhao, G., Ren, Y. \& Wang, Z. Microfabrication of dilute magnetic semiconducting $\mathrm{Ti}_{1}-\mathrm{xCo}_{\mathrm{x}} \mathrm{O}_{2}$ films using photosensitive sol-gel method. Thin Solid Films 519, 1985 (2011).

18. Chen, Y., Zhao, G. \& Yan, F. Ferromagnetic Co-doped ZnO film and fine patterns prepared using photosensitive sol-gel method. J. Sol-Gel Sci. Technol. 54, 325 (2010).

19. Kololuomaa, T., Kärkkäinen, A. H. O., Tolonen, A. \& Rantala, J. T. Lithographic patterning of benzoylacetone modified $\mathrm{SnO}_{2}$ and $\mathrm{SnO}_{2}: \mathrm{Sb}$ thin films. Thin Solid Films 440, 184 (2003).

20. Tohge, N., Shinmou, K. \& Minami, T. Effects of UV-Irradiation on the formation of oxide thin films from chemically modified metal-alkoxides. J. Sol-Gel Sci. Technol. 2, 581 (1994).

21. Tadanaga, K., Owan, T., Morinaga, J., Urbanek, S. \& Minami, T. Effects of UVirradiation on the formation of oxide thin films from chemically modified metalalkoxides. J. Sol-Gel Sci. Technol. 19, 791 (2000).

22. Shinmou, K., Tohge, N. \& Minami, T. Fine-patterning of $\mathrm{ZrO}_{2}$ thin films by the photolysis of chemically modified gel films. Jpn. J. Appl. Phys., 33, 1181 (1994).

23. Mehrotra, R. C. Chemistry of metal $\beta$-diketonates. Pure \& Appl. Chem. 60, 1349 (1988).

24. Zhao, G., Tohge, N. \& Nishii, J. Fabrication and characterization of diffraction gratings using photosensitive $\mathrm{Al}_{2} \mathrm{O}_{3}$ gel films. Jpn. J. Appl. Phys. 37, 1842 (1998).

25. Nakamoto, K., McCarthy, P. J., Ruby, A. \& Martell, A. E. Infrared spectra of metal chelate compounds. II. Infrared spectra of acetylacetonates of trivalent metals. J. Am. Chem. Soc. 83, 1066 (1961).

26. Holtzclaw Jr, H. F. \& Collman, J. P. Infrared absorption of metal chelate compounds of 1,3-diketones. J. Am. Chem. Soc. 79, 3318 (1957).

27. Leaustic, A., Babonneau, F. \& Livage, J. Structural investigation of the hydrolysiscondensation process of titanium alkoxides $\mathrm{Ti}(\mathrm{OR})_{4}(\mathrm{OR}=\mathrm{OPr}$-iso, $\mathrm{OEt})$ modified by acetylacetone. 2 . From the modified precursor to the colloids. Chem. Mater. 1, 248 (1989).

28. Percy, M. J., Bartlett, J. R., Woolfrey, J. L. Spiccia, L. \& Westa, B. O. The influence of $\beta$-diketones on the induction times for hydrolysis of zirconium(IV) alkoxides. J. Mater. Chem. 9, 499 (1999).

29. In, M. \& Prud'homme, R. K. Fourier transform mechanical spectroscopy of the sol-gel transition in zirconium alkoxide ceramic gels. Rheol Acta 32, 556 (1993).

30. Rim, Y. S. et al. Simultaneous modification of pyrolysis and densification for lowtemperature solution-processed flexible oxide thin-film transistors. J. Mater. Chem. 22, 12491 (2012).
31. Song, K. et al. Solution-processable tin-doped indium oxide with a versatile patternability for transparent oxide thin film transistors. J. Mater. Chem. 21, 14646 (2011).

32. Queraltó, A., Pérez del Pino, Á., Ricart, S., Obradors, X. \& Puig, T. Laser-induced metal organic decomposition for $\mathrm{Ce}_{0.9} \mathrm{Zr}_{0.1} \mathrm{O}_{2-\gamma}$ epitaxial thin film growth. J. Alloys Compd. 574, 246 (2013).

\section{Acknowledgments}

This work was supported by the National Research Foundation of Korea (NRF) grant funded by the Korean Ministry of Education, Science and Technology (MEST) [no. 2011-0028819].

\section{Author contributions}

Y.S.R. and H.S.L. contributed equally to this work. Y.S.R. designed the experimental concept and synthesized solutions. H.S.L. made devices and measured film properties. All authors discussed it and wrote the main manuscript text. The project was guided by H.J.K.

\section{Additional information}

Supplementary information accompanies this paper at http://www.nature.com/ scientificreports

Competing financial interests: The authors declare no competing financial interests.

How to cite this article: Lim, H.S., Rim, Y.S. \& Kim, H.J. Photoresist-Free Fully Self-Patterned Transparent Amorphous Oxide Thin-Film Transistors Obtained by Sol-Gel Process. Sci. Rep. 4, 4544; DOI:10.1038/srep04544 (2014).

This work is licensed under a Creative Commons Attribution-NonCommercialShareAlike 3.0 Unported License. The images in this article are included in the article's Creative Commons license, unless indicated otherwise in the image credit; if the image is not included under the Creative Commons license, users will need to obtain permission from the license holder in order to reproduce the image. To view a copy of this license, visit http://creativecommons.org/licenses/by-nc-sa/3.0/ 